\title{
Defining optimal vitamin D cut-off levels: The role of parathyroid hormone concentrations
}

\author{
Spyridon N. Karras, ${ }^{1}$ William B. Grant, ${ }^{2}$ Declan P. Naughton, ${ }^{3}$ Kalliopi Kotsa ${ }^{1}$
}

${ }^{1}$ First Department of Internal Medicine, Division of Endocrinology and Metabolism, AHEPA Hospital, Thessaloniki, Greece; ${ }^{2}$ Sunlight, Nutrition, and Health Research Center, San Francisco, CA, USA; ${ }^{3}$ School of Life Sciences, Pharmacy and Chemistry, Kingston University, Penrhyn Road, Kingston upon Thames, KT1 2EE, UK

\section{Dear Editor,}

We read with interest the recent article by Katrinaki et al. ${ }^{1}$ The authors report on cross-sectional values of serum 25-hydroxyvitamin D [25(OH)D] concentrations from a large Mediterranean cohort in Crete, Greece. One of the main findings of the study was the sharp decline of parathyroid hormone (PTH) concentrations below the upper reference range of 65 $\mathrm{pg} / \mathrm{ml}$, with a non-significant decrease above $\sim 20 \mathrm{ng} /$ $\mathrm{ml} 25(\mathrm{OH}) \mathrm{D}$. This led the authors to conclude that a cut-off level of $20 \mathrm{ng} / \mathrm{ml}$ is optimal to avoid secondary hyperparathyroidism in this specific population.

The study provides useful, novel, large-scale results from a Mediterranean region where vitamin D deficiency is highly prevalent. ${ }^{2}$ These findings, however, contradict a previous large-scale study in the U.S. which found that PTH decreased monotonically to $25(\mathrm{OH}) \mathrm{D}$ concentrations above $70 \mathrm{ng} / \mathrm{mL} .^{3}$ Although of potential interest, a continuous report of the PTH curve with regard to higher $25(\mathrm{OH}) \mathrm{D}$ concentrations

Key words: Cut-off levels, Parathyroid hormone, Vitamin D

Address for correspondence: Spyridon N. Karras, Tel./Fax: +30-237-302-1922, E-mail: karraspiros@yahoo.gr

Received: 25-09-2016, Accepted: 03-10-2016 is not provided in the paper by Katrinaki et $\mathrm{al}^{1}$ and the authors report metabolic parameters inversely correlated with 25OHD in Figure 3, with no plateau or saturation. ${ }^{1}$ In the abovementioned large-scale study, ${ }^{3}$ a significant segment of the population with normal PTH levels $(<65 \mathrm{pg} / \mathrm{ml})$ manifested frank vitamin $\mathrm{D}$ deficiency, indicating that determination of both 25(OH)D and PTH in the individual setting is essential for providing optimal decisions in the daily clinical practice, rather than a single $25(\mathrm{OH})$ D measurement based on a specific cut-off point. In addition, health benefits have been reported in a plethora of observational studies for $25(\mathrm{OH}) \mathrm{D}$ concentrations $>30 \mathrm{ng} / \mathrm{mL}^{4}$

Further specific concerns regarding the interpretation of study findings lie in the accuracy of the analyses, and in particular the $25(\mathrm{OH}) \mathrm{D}$ results determined by chemiluminescence, especially the claim that 'the majority or protein-bound 25-(OH)D was released'. Evidence supporting this statement is absent, as is a reference to qualify the comment contradicted in the literature. In conclusion, we believe that the available evidence ${ }^{3-5}$ does not support the notion that $25(\mathrm{OH})$ D concentrations of $20 \mathrm{ng} / \mathrm{mL}$ could be considered as the normal cut-off value for estimating vitamin D status. Additional studies of vitamin D replacement and treatment showing changes in specific patientimportant outcomes ${ }^{4}$ at certain levels of $25(\mathrm{OH}) \mathrm{D}$ are needed and would provide higher quality evidence that would lead to stronger recommendations. 


\section{CONFLICT OF INTEREST}

The authors confirm no conflict of interest.

\section{GRANTS OR FELLOWSHIP SUPPORTS}

None.

\section{REFERENCES}

1. Katrinaki M, Kampa M, Margioris A, Castanas E, Malliaraki N, 2016 Vitamin D levels in a large Mediterranean cohort: reconsidering normal cut-off values. Hormones (Athens) 15: 205-223.

2. Karras S, Paschou SA, Kandaraki E, et al, 2016 Hypovi- taminosis D in pregnancy in the Mediterranean region: a systematic review. Eur J Clin Nutr 70: 979-986.

3. Valcour A, Blocki F, Hawkins DM, Rao SD, et al, 2012 Effects of age and serum 25-OHvitamin D on serum parathyroid hormone levels J Clin Endocrinol Metab 97: 3989-399.

4. Holick MF, Binkley NC, Bischoff-Ferrari HA, 2011 Evaluation, treatment, and prevention of vitamin D deficiency: an Endocrine Society clinical practice guideline. J Clin Endocrinol Metab 96: 1911-1930.

5. Pludowski P, Holick MF, Pilz S, et al, 2013 Vitamin $\mathrm{D}$ effects on musculoskeletal health, immunity, autoimmunity, cardiovascular disease, cancer, fertility, pregnancy, dementia and mortality- a review of recent evidence. Autoimmun Rev 12: 976-989.

\section{Dear Editor,}

We would like to respond to the letter of Karras et al as follows:

The first point made in the letter concerns the finding of a monotonical PTH decrease to 25- $(\mathrm{OH})$ $\mathrm{D}$ concentrations exceeding $70 \mathrm{ng} / \mathrm{mL}$ by Valcour et al. ${ }^{1}$ This important report presents data from an impressive number of paired PTH/25-(OH)D measurements $(\sim 313.000)$, which provide strong evidence for an age-dependent PTH/25-(OH)D continuum. The authors also suggest that serious vitD deficiency may be accompanied by normal PTH levels, while biochemical hyperparathyroidism may be evident in both the presence and absence of vitD sufficiency.

It should be noted, however, that no information is offered about the subjects of the study, including the reason for $\mathrm{PTH} / 25-(\mathrm{OH}) \mathrm{D}$ testing or data regarding $\mathrm{Ca}$ and vitD supplementation, season of sample collection, renal function indices and serum $\mathrm{Ca}$ levels (all known to substantially affect $25-(\mathrm{OH}) \mathrm{D}$ values), and no confounders were taken into account when evaluating the relationship between PTH and 25-(OH) D. Confirmation of whether the above findings are identical when gender, age and seasonal effects on 25-(OH)D levels are taken into consideration would be of considerable interest.

While we cannot easily argue with the sheer size of the data presented by Valcour et al, it is well documented that the dynamic interrelationship between PTH and 25-(OH)D levels is always strongly affected by calcium intake and absorption and vitD supplementation, as discussed in detail in our article (p216, §2). ${ }^{2}$ This limitation applies to the majority of published reports, including our own and that by Valcour et al.

Furthermore, the relationship between PTH and 25- $(\mathrm{OH}) \mathrm{D}$ (and especially between PTH and Ca, which was not explored) is part of a feedback loop and, like all feedbacks involving one or two factors in biological systems, is expected to follow a hyperbolic curve (analyzed in detail in the excellent book by Albert Goldbeter. ${ }^{3}$

The age-associated PTH elevation, which might confound correlations between VitD status and other laboratory indices, is also acknowledged in our article (p215, §1). More specifically, using age and gender as confounders in multivariate analysis, we observed a plateau of $\mathrm{Ca}$ serum levels and normalization of

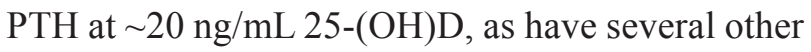
groups ${ }^{4}$ with a further non-significant decrease with increasing 25-(OH)D concentrations. Since the main focus of our study was to determine the total serum $25-(\mathrm{OH}) \mathrm{D}$ levels on the island of Crete and compare a $25-(\mathrm{OH}) \mathrm{D}$ threshold for our population with the internationally proposed cut-offs for VitD sufficiency, we did not pursue the continuity of the PTH curve with regard to higher $25-(\mathrm{OH}) \mathrm{D}$ concentrations $(>30$ $\mathrm{ng} / \mathrm{mL}$ ) ensuring vitD adequacy. The same applies to metabolic parameters inversely correlated with 25-(OH)D levels: our goal was to document associa- 
tions in our population and no plateau or saturation was evaluated.

We too, like the authors, expressed skepticism about clinical decisions based on single 25-(OH)D measurements, especially in light of the documented substantial seasonal variation of $25-(\mathrm{OH}) \mathrm{D}$ values: "... caution should be exercised when single "snapshot" measurements of 25-(OH)D form the basis for recommendations on VitD supplementation and associations with various health outcomes" ( $p 215, \S 3$ and $\mathrm{p} 218$ conclusion). We are not, however, aware of international guidelines suggesting a baseline measurement of PTH in the evaluation of 25-(OH)D levels in everyday clinical practice.

As for the issue of health benefits reported for higher 25-(OH)D concentrations, we acknowledge that "while the major biological effect of PTH in our cohort was manifested at 25-(OH)D levels below $20 \mathrm{ng} / \mathrm{mL}$, potentially harmful non-skeletal effects at $25-(\mathrm{OH}) \mathrm{D}$ concentrations between $20-30 \mathrm{ng} / \mathrm{mL}$ cannot be excluded" (p216, §2).

In our study, serum $25-(\mathrm{OH}) \mathrm{D}$ was measured using the LIAISON 25-OH Vitamin D TOTAL Assay (DiaSorin Inc), a direct chemiluminescence assay, also used by Valcour et al (Table 2). A validation procedure (described in detail in our article p.209-210) yielded $\sim 100 \%$ recovery of $25-(\mathrm{OH}) \mathrm{D}$, thus confirming that this assay measured the total amount of $25-(\mathrm{OH}) \mathrm{D}$ present in samples. Although we are fully aware of the lack of agreement regarding the various methods used to measure $25-(\mathrm{OH}) \mathrm{D}$, detailed discussion of this issue was beyond the scope of our work.

To our knowledge, the debate surrounding "normal/ adequate" 25-(OH)D levels remains unresolved and is an extremely complicated and constantly evolving issue. The US Endocrine Society recommends a 30 $\mathrm{ng} / \mathrm{mL}$ cut-off, ${ }^{5}$ while the US Institute of Medicine (IOM) is in favor of using a $20 \mathrm{ng} / \mathrm{mL}$ cut-off, ${ }^{6}$ and both tenets are well founded. Our current data lead us to conclude that the IOM's 2011 guidelines better reflect the physiology of our population.
The concept of moving away from fixed values ( $20 \mathrm{vs} 30 \mathrm{vs} 40 \mathrm{ng} / \mathrm{mL}$ ) to define vitD sufficiency and manage patients based on an age-dependent $\mathrm{PTH} / 25$ $(\mathrm{OH}) \mathrm{D}$ continuum, as Valcour et al propose, ${ }^{1}$ is an attractive one but needs to be corroborated.

Finally, we are in total agreement with and fully support the need for additional, randomized control trials of vitD replacement in order to obtain unequivocal evidence that would lead to safe recommendations and implementation of strategies to confront the multifaceted implications of vitD deficiency. In this light and to underscore the magnitude of this endeavor, we expressly chose to quote Anthony Norman at the end of our article: "normal 25-(OH)D serum levels" are those that support all VDR-containing target organs in all the world's population groups".?

\section{Sincerely yours, Niki Malliaraki et al}

\section{REFERENCES}

1. Valcour A, Blocki F, Hawkins DM, Rao SD, 2012 Effects of age and serum 25-OH-vitamin D on serum parathyroid hormone levels J Clin Endocrinol Metab 97: 3989-3995.

2. Katrinaki M, Kampa M, Margioris A, Castanas E, Malliaraki N, 2016 Vitamin D levels in a large Mediterranean cohort: reconsidering normal cut-off values. Hormones (Athens) 15: 205-223.

3. Albert Goldbeter 1996 Biochemical Oscillations and Cellular Rhythms, The molecular bases of periodic and chaotic behavior. Cambridge University Press.

4. Sai AJ, Walters RW, Fang X, Gallagher JC, 2011 Relationship between vitamin $\mathrm{D}$, parathyroid hormone, and bone health. J Clin Endocrinol Metab 96: E436-E446.

5. Holick MF, Binkley NC, Bischoff-Ferrari HA, et al, 2011 Evaluation, treatment, and prevention of vitamin D deficiency: an Endocrine Society clinical practice guideline. J Clin Endocrinol Metab 96: 1911-1930.

6. Ross AC, Manson JE, Abrams SA, et al, 2011 The 2011 report on dietary reference intakes for calcium and vitamin D from the Institute of Medicine: what clinicians need to know. J Clin Endocrinol Metab 96: 53-58.

7. Norman A, 2008 From vitamin D to hormone D. Am J Clin Nutr 88: Suppl: 491-499. 